\title{
Einige Gedanken Ihres Verlegers
}

Während die aktuelle Weltlage uns alle beschäftigt und viel über Globalisierung und den offensichtlich drohenden Zusammenprall von Kulturen geredet wird, ist es vielleicht der richtige Zeitpunkt, um Ihnen einige unserer Gedanken zu unserer verlegerischen Zukunft in diesen ökonomisch recht unsicheren Zeiten mitzuteilen.

Das Verlagshaus Karger, seit seiner Gründung vor 112 Jahren unabhängig und gänzlich eigenfinanziert, strebt auch in Zukunft danach, diese Position zu bewahren. Während STM-Verlage (Wissenschaft, Technik und Medizin) sich zu immer weniger, dafür immer größeren Firmen vereinen, ist Karger stolz darauf, als eigenständige Firma seine Politik der Zusammenarbeit mit den verschiedensten Partnern, speziell auch im Internet-Bereich, weiterzuführen. Wir sind überzeugt, dass dies auch im besten Interesse der wissenschaftlichen Gemeinschaft ist.

Wir halten weiterhin engen Kontakt mit unseren etablierten Niederlassungen weltweit, verstärken aber unsere Präsenz mit neuen Büros in Beijing und St. Petersburg sowie einem Joint-Venture-Einsatz im Nahen Osten. Unsere Unabhängigkeit erlaubt uns, unsere Entscheidungen auf der Basis von längerfristigen Erwägungen und wissenschaftlichem Verdienst zu fällen, statt aufgrund einer kurzfristigen Investitionsrentabilität.

Die Qualität unseres Publikationsprogrammes hängt von Ihnen - Autoren, Herausgebern, Begutachtern und Lesern - ab, und wir anerkennen Ihren Einsatz mit großer Dankbarkeit. Wir bemühen uns sehr um erstklassigen Kundendienst, faire Preisgestaltung und raffinierte, benutzerfreundliche Programme.

Es ist uns bewusst, dass wir als Verlag eine wesentliche Rolle in der Kette der Informationsübermittlung in Ausbildung und Forschung spielen und so mithelfen, die Welt der Wissenschaft näher zueinander zu bringen. Davon lassen wir uns nicht abbringen, und wir bedanken uns bei Ihnen für Ihre bisherige und zukünftige Zusammenarbeit, die wir sehr schätzen.

Dr. Thomas Karger Steven Karger

\begin{tabular}{ll}
\hline KARGER & ( ) 2002 S. Karger GmbH, Freiburg \\
$\begin{array}{l}\text { Fax +49 7614520714 } \\
\begin{array}{l}\text { E-mail Information@Karger.de } \\
\text { www.karger.com }\end{array}\end{array}$ & $\begin{array}{l}\text { Accessible online at: } \\
\text { www.karger.com/journals/cga }\end{array}$ \\
&
\end{tabular}

